http://dx.doi.org/10.4314/gjl.v6i2.6

\title{
TWISWAHILI OR KISWATWILI: A STUDY OF PARALLEL PROVERBS IN AKAN (TWI) AND KISWAHILI
}

\author{
Obádélé Kambon and Josephine Dzahene-Quarshie
}

\begin{abstract}
In Akan and Kiswahili, there are several proverbs that express the same underlying idea, oftentimes in the exact same or similar ways. There are several possible reasons why these parallel proverbs exist. In one line of thinking, the similarities may be due to contact phenomena facilitating shared cultural and/or historical experiences. Another perspective is that the similarities may be due to the demonstrably genetic relationship between Akan and Kiswahili as languages of the Niger-Congo phylum. In this study, however, we will examine these proverbs in parallel or near-parallel and demonstrate that regardless of the facts of the two aforementioned lines of inquiry, they attest to a shared African worldview and can be analyzed in terms of measured proximity and similarity.
\end{abstract}

Keywords: Akan, Swahili, proverb, comparison, proximity, similarity, PPP matrix

\subsection{Introduction}

Although easily identifiable within their cultural-linguistic context, proverbs tend to elude a universal consensus definition. Various definitions have been proposed over the years. The Merriam-Webster Dictionary defines it as "a brief popular saying... that gives advice about how people should live or that expresses a belief that is generally thought to be true." Here, a definition is given based on prescriptiveness in that it directs people as to how they should live or confirms their beliefs. 
Nabifar (2013) provides a more comprehensive definition of the proverb as:

a short, generally known sentence of the folk which contains wisdom, truth, morals, and traditional views in a metaphorical, fixed and memorizable form, which are handed down from generation to generation and since they belong to the common knowledge of basically all native speakers they are indeed very effective devices to communicate wisdom and knowledge about human nature and the world at large. (Nabifar 2013:2287)

This definition takes into account various evaluative criteria with regard to what a proverb is in terms of its content, form and its link to culture and history. However, since we are discussing African proverbs specifically, it is appropriate to note a few African meta-proverbs by way of definitions:

1. Bí òwe ò bá jọ òwe, a

$\begin{array}{lllll}\text { When proverb NEG } & \text { COND resemble proverb, 1PL.SBJ } \\ \text { kì í } & \text { pa á. } & & \end{array}$

NEG.HAB cite 3SG.OBJ

'If a proverb does not apply to a situation, one does not cite it. (Owomoyela 2005: 159) (Yorùbá)

2. Asem ba a, na abe-buo a-ba.

issue come COND, FOC proverb-citing PRF-come

'When the occasion arises, a proverb comes to mind.' (Akan) (Appiah, Appiah, and Agyeman-Duah 2001: 247)

These meta-proverbs provide a sense of the importance of appropriateness in a given context. The idea is that a defining feature of proverbs and that which imbues them with a sense of truth is their propriety with relation to the context in which they are cited. This is in alignment with the ancient African concept of 'truth, right-doing, righteousness, justice, rightness, orderly management' that also includes ideas of harmony, balance and propriety, which are fundamental to the African worldview (Dickson 2006: 236).

A belief that is shared by many scholars is the potential global/universal application of a large percentage of proverbs irrespective of their geographical origin. It is also a fact that even if not identical in lexical composition, some proverbs from different languages may express the same concepts or ideas because some situations are common to human experience (Škara 1995). 
Nevertheless, it is also true that because proverbs tend to be metaphorical and highly historical, and culturally determined/motivated, some proverbs, like metaphors, may require knowledge of the specific cultural setting in order to fully understand them (Lakoff and Johnson 2008). An example of such a proverb in Akan is:

3. N-ye obi NEG-be no ara DEF merely gye-e receive-COMPL

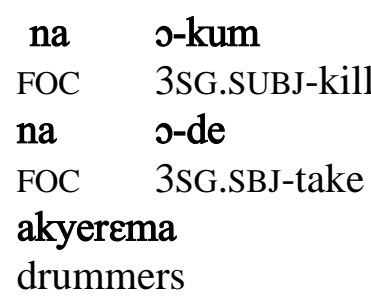
head for execution.' (Appiah, Appiah, and Agyeman-Duah 2001: 303)

\author{
Antwi; Boasiako \\ A. \\ B. \\ ne tiri \\ 3SG.POSS head
}

This proverb is said to emanate from a historical incident. On one account, one Dben Antwi impregnated a royal wife of Ntim Gyakari, the ruler of Denkyira, who was entrusted to his care and was executed for the offense (Reindorf 2007: 52). On another account, a royal returned from war to find his wife pregnant and one Duodu Antwi claimed responsibility to absolve the true culprit who was the ruler of the Asante nation himself (Appiah, Appiah, and Agyeman-Duah 2001: 303). In either case, it is said that Antwi brought his execution upon himself.

Another proverb originating from historical circumstances is the following:

4. Ntim Gyakari

N. Gy.

Feyiase

F.

'Ntim Gyakari carried his nation and wrecked her at Feyiase (town).' (Appiah, Appiah, and Agyeman-Duah 2001: 211)

The proverb highlighted in (4) is rooted in a historical reference to the AsanteDenkyira war in which the Denkyira nation fell to Asante at the town of Feyiase. In light of these proverbs related to a culturally and historically specific local context, Nabifar notes that, nevertheless, there is a "common, universal morality, guide for the practice of virtue, similar in all countries, if not in the form, at least in the message; and those which are particular, borne from a historical fact, a local custom or a specific event. They have their own identity signs which characterize the place or time of origin." (Nabifar 2013:2289-90). 
A major feature of proverbs is their deployment in contexts other than those in which they originated such that they relate to the situation at hand by means of analogy to the original situation referenced directly. As such, proverbs exemplify the concept of cognitive economy. In other words, one proverb can be used in various contexts without imposing upon the speaker the necessity of coming up with new constructions in each new instance in which an analogous reply is necessary. According to Holland and Quinn (1987), "As compact expressions of important cultural knowledge, proverbs combine a cognitive economy of reasoning with pragmatic force aimed at influencing other people" (Holland and Quinn 1987:152). This sentiment is echoed in the notion that "Cognitively, proverbs are mentally economical, since from one particular situation presented in them we can understand many others" (Moreno 2005: 42).

Elaborating on the concept of cognitive economy in categorization, Rosch (1978) explains that:

as an organism, what one wishes to gain from one's categories is a great deal of information about the environment while conserving finite resources as much as possible. To categorize a stimulus means to consider it, for purposes of that categorization, not only equivalent to other stimuli in the same category but also different from stimuli not in that category. On the one hand, it would appear to the organism's advantage to have as many properties as possible predictable from knowing any one property, a principle that would lead to formation of large numbers of categories with as fine discriminations between categories as possible. (Rosch 1978:28-9)

Thus, while cognitive economy offers substantive benefits, the flip side of the equation is that "the price of this cognitive economy is a bit of rigidity in interpreting the world and a certain slowness in recognizing or learning new models" (Holland and Quinn 1987:391). Thus, as with many phenomena, the diverse application and potential for utilization in a variety of contexts serves as a double-edged sword in the sense that, as with many things, this attribute may be both a strength and a weakness at the same time.

In the literature, some studies have been done on proverbs including comparative studies between languages from perspectives based on characteristic features of proverbs and the cognitive processes associated with their use (Škara 1995, Hong-mei 2013, Gluski 1989, Nabifar 2013, Ying 2013, Ulatowska et al. 2000, Mieder 2003, Moreno 2005). The current study embarks upon a comparative study between Akan (Asante) and Kiswahili (Tanzanian) proverbs. Historically, Akan and 
Kiswahili belong to the same African language family, namely the Niger-Congo phylum, although they belong to different sub-groups. ${ }^{1}$ Nonetheless, there is evidence of some linguistic affinity between them (Welmers 1963, Osam 1993, DzaheneQuarshie 2016). Having established linguistic affinity between Akan and Bantu and by extension Kiswahili, the possibility of a shared cultural and historical experience in the distant past cannot be ruled out.

It is evident from a range of Akan (Asante Twi) and Kiswahili proverbs that several of them are wholly or partly identical in terms of lexical and/or syntactic composition. There are still others that are not parallel in content but parallel in terms of meaning and application. The focus of this paper, therefore, is to examine these proverbs in parallel or near-parallel and demonstrate that they attest to a shared African worldview - most simply put: a common way of viewing the world as African people.

Having given a general introduction, we will now turn our attention to our methodology, followed by our conceptual framework which makes a link between Proximity of People and Similarity of Proverbs of Akan and Kiswahili speakers. We will subsequently introduce a novel framework that we term the People's Proverb Proximity (PPP) Matrix, which will serve as a method of representing the correlation between proximity along various dimensions and similarity of proverbs. We will then provide an analysis of what we term KiswaTwili² (parallel Akan (Asante Twi) and Kiswahili) proverbs within the framework of the aforementioned PPP Matrix. Finally, we will present our overall findings and conclusions.

\subsection{Methodology and Data}

In gathering the data for the study, proverbs from several texts (Appiah et al. 2001; Ampem 1998; Ndalu and King'ei 1989; Wamitila 2006) were purposefully selected primarily from Asante Twi (representing Akan) and Tanzanian Kiswahili (representing Kiswahili). As such, proverbs that have identical or similar equivalents with the same or almost the same meaning in the two languages were identified and grouped together. Next, pairs of proverbs which are not necessarily lexically or semantically parallel but depict or express the same or similar ideas were selected.

\footnotetext{
${ }^{1}$ In an alternative and more preferable analysis, they belong to the common Négro-Egyptien phylum (cf. Obenga 1993).
} 
Our primary focus was on conceptual/semantic parallels or near-parallels with a secondary focus on identical or similar lexemes. We selected 60 proverbs as part of this exploratory study.

\subsection{Conceptual Framework: People Proximity and Proverb Similarity}

At this point, we will introduce a framework of dimension of proximity as a measure of proverb similarity. We briefly discuss the dimension of proximity between Akan and Kiswahili speaking people in terms of a Biological (including physiological, anatomical, genetic, phenotypical, etc.) proximity, Cosmological proximity, Cultural proximity and Environmental proximity. From these dimensions of proximity comes our hypothesis that the closer these dimensions of proximity are to each other, the greater the degree of similarity between proverbs.

\subsection{Cultural Distance and Proximity}

We found that in the literature, there were established conceptual frameworks in which terms such as cultural proximity and cultural distance have been introduced. Cultural proximity may be generally understood as "the tendency to prefer media products from one's own culture or the most similar possible culture" (Straubhaar and Elasmar 2003: 85). Cultural Distance, on the other hand, is typically used in business and marketing and is defined "as a function of differences in values and communication styles that are rooted in culture" (demographic or organizational) (Lojeski and Reilly 2008: 665). While these concepts share similar terminology, what we mean by proximity is entirely different and will be explicated below.

With regard to proximity, our use of the term is more closely related to notions that the closer people are geographically, the closer they tend to be culturally, and in various other dimensions due primarily to environmental and other intervening factors. This idea can be found in the literature as seen in quotes such as "There has never been any doubt on the part of observers reflecting on the matter that there is a connection between geographical proximity and the cultural similarity of ethnic units" (Milke, Chrétien, and Kroeber 1949: 237). Also, similar notions can be found in quotes that address cultural distance, such as "[C]ultural differences can be assessed at different levels of analysis, namely by contrasting national differences in values and norms (cultural distance) with individuals' perceptions of those differences (psychic distance)" (Pinto, Cardoso, and Werther 2010: 4).

It is clear that genetically the Swahili people and the Akan people are of the African/Black race, except that some Swahili people are of mixed race (as a result of the long-standing relationship between the Swahili Coast and various groups of 
Arabs). Physically, although Ghana and Tanzania are situated in different parts of Africa (West and East) it can be argued that they are all situated in the middle belt of Africa, a fact that is supported by their belonging to the same language family, NigerCongo. Further, the climates in the two countries are generally similar. Both have coastal areas, tropical forests as well as arid lands. Due to these similar climates and environments, food stuffs are fairly uniform.

Cosmologically and culturally the two societies share, to a large extent, similar worldviews as expressed through indigenous spiritual systems. In both cultures, family and relationship values generally overlap. One significant distinction is found in the fact that the Akan people are historically matrilineal while the Swahili people are patrilineal. However, Nurse et al. (1985) argue that the Swahili society were originally matrilineal but shifted subtly to patrilineal as ideologies and symbols were gradually transformed (Nurse, Spear, and Spear 1985).

In the two societies, proverbs are also used in similar contexts. So, in terms of dimensions of proximity as a measure of proverb similarity, the level of similarity is quite high although there are marked differences in some variables such as the foods and other aspects of material culture that vary.

\subsection{Dimensions of proximity as measure of proverb similarity}

We now introduce the concept of dimensions of proximity and similarity. Proximity relates to how close the two (or more) groups of people are to each other with respect to four (4) dimensions. These dimensions are:

\section{a. Biological proximity}

Biological proximity relates to similarity in terms of types of people genetically, phenotypically, physiologically, anatomically, racially, etc.

b. Cosmological proximity

Cosmological proximity can be understood as similarity of worldview, spirituality, and other related notions between groups of people.

c. Cultural proximity

Cultural proximity is similarity in material culture, ideational culture, social culture, etc.

\section{d. Environmental proximity}

Finally, Environmental proximity relates to similarity in terms of physical location, climate, topographical features and other such factors between groups of people. 
These dimensions of proximity inform our fundamental hypothesis that the closer these and potentially other dimensions of "people proximity" are to each other, the greater the degree of similarity between proverbs of the peoples in question. A related assumption is that greater closeness in one dimension may make up for greater distance in another. As such, we will test these hypotheses against the data found for Akan (represented here by Asante Twi) of Ghana and Kiswahili proverbs of Tanzania.

\subsection{People's Proverb Proximity (PPP) Matrix}

Just as proximity can be measured with regard to the people who originate from the same place and use proverbs, corresponding dimensions of similarity can be measured with regard to proverbs. These dimensions of similarity, when combined with "people proximity" dimensions help us to gauge on a parallel proverb-byproverb basis how close a set of proverbs from one language group is to that of another.

These dimensions of proverb similarity include:

\section{a. Conceptual/Semantic similarity}

The primary factor relating to conceptual/semantic similarity is for there to exist parallel overall meanings between pairs of proverbs.

\section{b. Contextual similarity}

This dimension calls for parallel contexts in which the proverbs are used. In other words, different proverbs may be used in the same context to convey similar overall meanings or concepts.

\section{c. Lexical similarity}

Lexical similarity may be understood as the utilization of parallel lexemes in the selected set of proverbs. For example, a given pair of proverbs seen as being parallel may use animals like the tortoise to convey an idea of slowness or honey to convey an idea of sweetness in proverbs.

\section{d. Syntactic/Structural similarity}

The last dimension of proverb similarity identified is that of parallel syntactic structures used in each of the proverbs compared. This may be in terms of basic SVO structure or in the use of negation or similar tense/aspect systems in the proverbs being compared. 
The nexus or interface between these people/proverb dimensions can be represented in tabular format in what we term the People's Proverb Proximity (PPP) Matrix:

Table 1: People's Proverb Proximity (PPP) Matrix

\begin{tabular}{l|l|l|l|} 
Conceptual/ & Contextual & Lexical & Syntactic/ \\
Semantic & Similarity & Similarity & $\begin{array}{l}\text { Structural } \\
\text { Similarity }\end{array}$ \\
\hline Similarity & & &
\end{tabular}

Biological
proximity

Cosmological

proximity

Cultural

proximity

Environmental proximity

In both Akan (Asante Twi) and Kiswahili languages, proverbs usually adhere to grammatical rules, although there may be instances where the structure of some proverbs may not follow the general grammatical rules as in the case of some attested Efik proverbs (Mensah 2010). There are several structural types involved, from oneargument constructions, which may constitute phrases, to complex constructions consisting of main and subordinate clauses. As posited in the literature, proverbs in both languages are usually made up of two parts; subject and verb or subject and predicate for simple sentences or a main clause and a subordinate clause for complex sentences (cf. Škara 1995).

\subsection{Analysis of parallel KiswaTwili proverbs}

We will now turn our attention to an analysis of KiswaTwili proverbs using the PPP matrix framework. Our first parallel set features a pair of Akan (Asante Twi) proverbs that use different wording to convey the same core notion and a pair of similar Kiswahili (Tanzania) proverbs: 
5.

$\begin{array}{lll}\text { a. Okoto } & \text { n-wo } & \text { anomaa. } \\ \text { crab } & \text { NEG-birth } & \text { bird } \\ \text { 'The crab } & \text { doesn't give birth to a bird.' (Appiah, Appiah, and }\end{array}$ Agyeman-Duah 2001: 165)

b. Adowa/eyuo n-wo ba na

royal antelope/black duiker NEG-birth child CONJ

o-n-ko-se owansane.

3SG-IMP-EGR-resemble bushbuck.

'The royal antelope/black duiker does not give birth to its child for it to resemble a bushbuck.' (Appiah, Appiah, and Agyeman-Duah 2001: 98)

c. Mtoto wa nyoka ni nyoka.

child GEN snake be snake.

'The child of a snake is a snake.' (Wamitila 2001: 193)

$\begin{array}{llll}\text { d. Mwana } & \text { simba } & \text { ni } & \text { simba. } \\ \text { son } & \text { lion } & \text { be } & \text { lion }\end{array}$

'The child of the lion is a lion.' (Wamitila 2001: 206)

These proverbs evince a degree of environmental proximity in the sense that the royal antelope, black duiker and the lion are African animals while the crab and the snake are also found in Africa in addition to other places. Because of similar environments, the KiswaTwili proverb set reference these specific animals while they likely would not feature prominently in proverbs from, say, the arctic circle. The set also displays a measure of cosmological proximity with regard to its latent commentary on the nature of the world in that one's offspring resembles one, biologically speaking. It also gives a view into ideas of definition and categorization. There is also a conceptual/semantic similarity, which forms the basis of our grouping the proverbs in the set together in that they are all expressing essentially the same concept in different ways. As such, this gives rise to what we refer to as contextual similarity in that they would be expected to be cited in similar contexts in relation to the core concept conveyed in each.

The PPP Matrix expressing the intersection of People Proximity and Proverb Similarity is shown below in Table 2 . 
Table 2: KiswaTwili Set 1 PPP Matrix

\begin{tabular}{|l|l|l|l|l|}
\hline & $\begin{array}{l}\text { Conceptual/Semantic } \\
\text { Similarity }\end{array}$ & $\begin{array}{l}\text { Contextual } \\
\text { Similarity }\end{array}$ & $\begin{array}{l}\text { Lexical } \\
\text { Similarity }\end{array}$ & $\begin{array}{l}\text { Syntactic/ } \\
\text { Structural } \\
\text { Similarity }\end{array}$ \\
\hline $\begin{array}{l}\text { Biological } \\
\text { proximity }\end{array}$ & & & \\
\hline $\begin{array}{l}\text { Cosmological } \\
\text { proximity }\end{array}$ & & & \\
\hline $\begin{array}{l}\text { Cultural } \\
\text { Proximity }\end{array}$ & & & \\
\hline $\begin{array}{l}\text { Environmental } \\
\text { proximity }\end{array}$ & & & \\
\hline
\end{tabular}

KiswaTwili Proverb Set 2 also shows a connection along the various dimensions of proximity and similarity proposed. These parallel proverbs are shown below:

6.
a. Wo-pere wo ho di aborobe a, 2SG.SUBJ-struggle2SG.POSS REFL eat pineapple COND, wo-di no bun.
2SG.SUBJ-eat 3SG.INAN.OBJ unripe.

'If you are in a hurry to eat a pineapple, you end up eating it green (a green one).' (Opoku 1997: 129)

b. Mstahimilivu hula mbivu.

patient-person eat ripe-fruits.

'A patient man eats ripe fruits.' (Wamitila 2001: 202)

The corresponding KiswaTwili Set 2 PPP Matrix is provided below: 
Table 3: KiswaTwili Set 2 PPP Matrix

\begin{tabular}{|l|l|l|l|l|}
\hline & $\begin{array}{l}\text { Conceptual/Semantic } \\
\text { Similarity }\end{array}$ & $\begin{array}{l}\text { Contextual } \\
\text { Similarity }\end{array}$ & $\begin{array}{l}\text { Lexical } \\
\text { Similarity }\end{array}$ & $\begin{array}{l}\text { Syntactic/ } \\
\text { Structural } \\
\text { Similarity }\end{array}$ \\
\hline $\begin{array}{l}\text { Biological } \\
\text { proximity }\end{array}$ & & & \\
\hline $\begin{array}{l}\text { Cosmological } \\
\text { proximity }\end{array}$ & & & \\
\hline $\begin{array}{l}\text { Cultural } \\
\text { proximity }\end{array}$ & & & \\
\hline $\begin{array}{l}\text { Environmental } \\
\text { proximity }\end{array}$ & & & \\
\hline
\end{tabular}

As can be readily observed, each of the proverbs in this set refers to the ripening process and patience necessary to allow this natural process of plant biology to take place. While there is a literal mention of fruits, the notion of cognitive economy allows the citation of these proverbs in any context in which patience is regarded as necessary, making them similar in terms of contextual usage. The core conceptual/semantic correlation between proverbs is also evinced in this pairing, as this similarity is typically the basis for evaluating any pair or set of proverbs as being in parallel. Further, we find in this pairing that the nature of fruits is used to convey similar concepts with regard to the nature of the world comprising the cosmological and conceptual interface. The use of fruits to convey this notion of patience meets a criterion of empirical truth that is readily observed and known in the environment of the perceived world structure.

According to Rosch "the perceived world is not an unstructured total set of equiprobable co-occurring attributes. Rather, the material objects of the world are perceived to possess [...] high correlational structure" (Rosch 1978:29). As such, our individual and collective empirically-obtained knowledge about the objects in the environment and their nature becomes a crucial factor in terms of how said objects may feature in proverbs. A physical environment where fruits are abundant then becomes a milieu in which proverbs may appeal to that which is generally known about the said fruits in terms of the general attributes of such objects in the context of perceived world structure. Also worth noting is the lexical similarity in which 
Kiswahili generalizes over fruits as a cogent category while Akan mentions the pineapple specifically.

The flexibility of the PPP matrix is also apparent in that in the case where the lexical similarity is not as strong, it may be represented in a lighter shade to show that the correlation, while it indeed exists, is not complete.

In KiswaTwili Proverb Set 3, we find another parallel which appeals to proximate material cultures and cultural practices between the Akan and Waswahili 'Swahili people.'

7.

a. Ayie ba

a, na ye-pa

abetwafoo

Funeral come

COND, FOC 1PL.SUBJ-remove

palm-wine-tappers

kyew.

hat

'When the funeral arrives, we are polite to the palm-wine tapper.' (Appiah, Appiah, and Agyeman-Duah 2001: 310)

b. Msitukane

wagema

na ulevi

2SG-NEG-SBJ-insult

palm-wine tappers

CONJ drunkenness ungaliko.

3SG.INAN-COND-exists.

'While drunkenness persists, one should not insult palm-wine tappers.' (Wamitila 2001: 186) 
Table 4: KiswaTwili Set 3 PPP Matrix

\begin{tabular}{l|l|l|l}
$\begin{array}{l}\text { Conceptual/Semantic } \\
\text { Similarity }\end{array}$ & $\begin{array}{l}\text { Contextual } \\
\text { Similarity }\end{array}$ & $\begin{array}{l}\text { Lexical } \\
\text { Similarity }\end{array}$ & $\begin{array}{l}\text { Syntactic/ } \\
\text { Structural } \\
\text { Similarity }\end{array}$
\end{tabular}

Biological

proximity

Cosmological

proximity

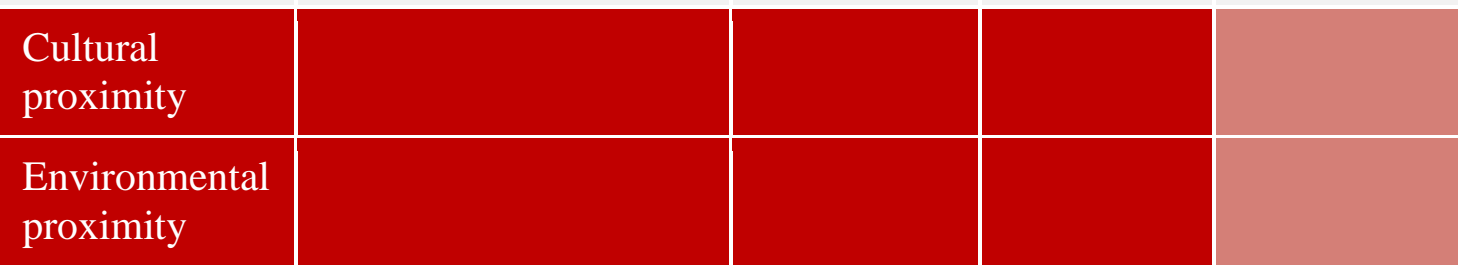

Again, in this KiswaTwili proverb set, we find evidence of environmental proximity and cultural proximity. The environmental proximity is seen in that both the Akan speakers and the Kiswahili speakers live in environments which feature palm trees and cultures that employ palm-wine tappers. Further, we find prescriptive statements or observations with regard to treatment of these palm-wine tappers, again appealing proximity with regard to cultural exigencies. In the set, we also observe conceptual/semantic similarity in terms of core meaning with regard to behavior towards palm-wine tappers in the literal sense and in a more metaphorical sense an appeal to the notion that, in times of need, those who may otherwise be regarded as of little consequence may loom large in importance under such circumstances. As the core meaning is similar, we also see an apparent contextual similarity in that the proverbs in both languages would likely be cited when a person becomes elevated in status temporarily due to circumstance or one is admonished to be tactful when dealing with someone on whom one is dependent, despite the fact that they are of a lower social or economic status. Additionally, we find lexical similarities with regard to expressions of politeness and palm-wine tappers. Finally, we observe a degree of syntactic/structural similarity in terms of the employment of conditional statements in each of the proverbs in the set.

KiswaTwili Proverb Set 4 is interesting in that each language employs a few ways to convey the same underlying thought as shown below: 
8.
a. Nsateaa
baako n-kukuru
ade $\varepsilon$.
finger
one NEG-lift thing
'One finger doesn't lift a load.' (Appiah, Appiah, and Agyeman-Duah 2001: 210)

b. Nsateaa

finger

$\begin{array}{ll}\text { baako } & \text { n-kum } \\ \text { one } & \text { NEG-kill }\end{array}$

dwie.

'One finger doesn't kill a louse.'
c. Mkono
mmoja hau-chinj-i
ng'ombe.
hand
one NEG-slaughter-NEG
cow

'A single hand cannot slaughter a cow.' (Wamitila 2001: 170)

d. Mkono

hand

mmoja hau-le-i

mwana.

'A single hand cannot nurse a child.' (Wamitila 2001: 171)

The KiswaTwili Set 4 PPP Matrix is shown below:

Table 5: KiswaTwili Set 4 PPP Matrix

\begin{tabular}{|l|l|l|l|l|}
\hline & $\begin{array}{l}\text { Conceptual/Semantic } \\
\text { Similarity }\end{array}$ & $\begin{array}{l}\text { Contextual } \\
\text { Similarity }\end{array}$ & $\begin{array}{l}\text { Lexical } \\
\text { Similarity }\end{array}$ & $\begin{array}{l}\text { Syntactic/ } \\
\text { Structural } \\
\text { Similarity }\end{array}$ \\
\hline $\begin{array}{l}\text { Biological } \\
\text { proximity }\end{array}$ & & & \\
\hline $\begin{array}{l}\text { Cosmological } \\
\text { proximity }\end{array}$ & & & \\
\hline $\begin{array}{l}\text { Cultural } \\
\text { proximity }\end{array}$ & & & & \\
\hline
\end{tabular}

Environmental

proximity 
In this set we see several points of intersection with regard to biological limitations common to the human condition. To illustrate the point, human beings do not have 10 legs and 15 fingers. Thus, we don't find proverbs that talk about such configurations. Because of how the human body is configured physiologically, using one finger to kill a louse or lift a heavy load is not a viable proposition. In other words, proverbs that talk about the human body and the human condition will naturally be similar because, as human beings, we all have the same basic physiological configuration from which we work. These proverbs are naturally similar because physiologically, human beings are similar. This point goes beyond worldview or environment to the human condition. For example, proverbs talk about death because human beings die and if we did not die, there would be no proverbs about death. We talk about the difficulty of doing things with one hand or one finger because the vast majority of us have more than one hand or one finger with which we operate. If we only had one hand or one finger, such proverbs would probably not exist because one finger would be the norm and, therefore, would not be remarkable per se. Biological and physiological advantages and disadvantages that come from our physiological makeup are the root of proverbs that discuss human physiology. As Africans were the first humans on the planet, the universality expressed in proverbs related to our anatomy, physiology or biology can be understood as the degree to which other populations retained or diverged from human (African) prototypicality in the areas of genotype, phenotype, anatomy, physiology, biology and behavior (Meredith 2011, Vigilant et al. 1991). Because all humans have retained similar physiological abilities and limitations referenced in the aforementioned proverbs, the dimension of biological proximity tends to be a manifestation of a common human condition as a result of millions of years of evolution except in cases where more nuanced distinctions may be made with regard to phenotype or other diversifying factors resulting from environment, etc. ${ }^{3}$ Embedded in the proverbs in example (8) is a latent discussion of the need for collectivity in endeavors of various sorts; this discussion appeals to both cultural practice as well as cosmological worldview.

\footnotetext{
${ }^{3}$ An example of human differences as a result of environment can be found in the following Akan

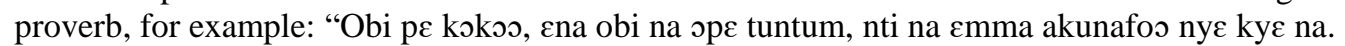
Someone likes [light, lit. red] colored women and another likes dark-skinned ones, that is why it is easy to share out widows. (In Akan society, when a man dies, the man who inherits him may marry his widows if he wishes. Hence: Every man has his taste)." (Appiah, Appiah, and Agyeman-Duah 2001: 40). The import is that because these are the two complexions that are found in traditional Akan society, and thus, these are all that are accounted for. If, on the other hand, the environment had given rise to a proliferation of pale white/pink-skinned people (apart from albinos), then we would encounter them in such proverbs as the one above.
} 
At a fundamental level, we see conceptual and concomitant contextual similarities which pervade this set of parallel proverbs. There is syntactic/structural similarity across the proverbs in that they all use negation to convey the underlying thought. Finally, there is a partial measure of lexical similarity in that each proverb speaks to what one hand (or finger) cannot do in the first portion of the utterance while the latter portion of the utterance is variable with regard to specific actions referred to.

KiswaTwili Proverb Set 5 is uncanny in its parallel identity across the two language groups in that the proverbs say almost exactly the same thing in the same way.

9.

a. Safo n-sa ne ho. healer NEG-heal 3SG.POSS body (REFL) 'The healer doesn't heal himself.' (Appiah, Appiah, and Agyeman-Duah 2001: 40)

b. Mganga ha-ji-gang-i.

healer NEG-REFL-heal-NEG

'A healer does not heal himself.' (Wamitila 2001: 162)

The relevant correspondences are illustrated below in the KiswaTwili Set 5 PPP Matrix: 
Table 6: KiswaTwili Set 5 PPP Matrix

\begin{tabular}{|l|l|l|l|l|}
\hline & $\begin{array}{l}\text { Conceptual/Semantic } \\
\text { Similarity }\end{array}$ & $\begin{array}{l}\text { Contextual } \\
\text { Similarity }\end{array}$ & $\begin{array}{l}\text { Lexical } \\
\text { Similarity }\end{array}$ & $\begin{array}{l}\text { Syntactic/ } \\
\text { Structural } \\
\text { Similarity }\end{array}$ \\
\hline $\begin{array}{l}\text { Biological } \\
\text { proximity }\end{array}$ & & & & \\
\hline $\begin{array}{l}\text { Cosmological } \\
\text { proximity }\end{array}$ & & & & \\
\hline $\begin{array}{l}\text { Cultural } \\
\text { proximity }\end{array}$ & & & & \\
\hline $\begin{array}{l}\text { Environmental } \\
\text { proximity }\end{array}$ & & & & \\
\hline
\end{tabular}

It is noticeable that both proverbs seem to speak more to cultural proscription rather than biological limitation, although it may be argued that there is some degree of the latter. However, the primary finding is that there is an obvious virtual identity in all respects with regard to the two parallel proverbs with regard to conceptual, contextual, lexical and structural similarity. This seems to answer the question in terms of whether this points to "a parallelism of thought" which stems from the mental construct in related people (Icke 2010: 34).

The next KiswaTwili Proverb is Set 6 as shown below:

10.

a. Kwasea ani te a, na agoro no a-gu. fool eye tear COND, FOC game DEF PRF-spill 'When the fool wises up, the game is finished.' (Appiah, Appiah, and Agyeman-Duah 2001: 180)

b. Mjinga a-ki-erevuka fool 3SG-COND-enlighten mwerevu yu mashakani. 'When a fool becomes enlightened, the wise man is in trouble.' (Wamitila 2001: 166)

Again, the KiswaTwili Set 6 PPP Matrix demonstrates the correspondences below: 
Table 7: KiswaTwili Set 6 PPP Matrix

\begin{tabular}{l|l|l|l}
$\begin{array}{l}\text { Conceptual/Semantic } \\
\text { Similarity }\end{array}$ & $\begin{array}{l}\text { Contextual } \\
\text { Similarity }\end{array}$ & $\begin{array}{l}\text { Lexical } \\
\text { Similarity }\end{array}$ & $\begin{array}{l}\text { Syntactic/ } \\
\text { Structural } \\
\text { Similarity }\end{array}$
\end{tabular}

Biological proximity

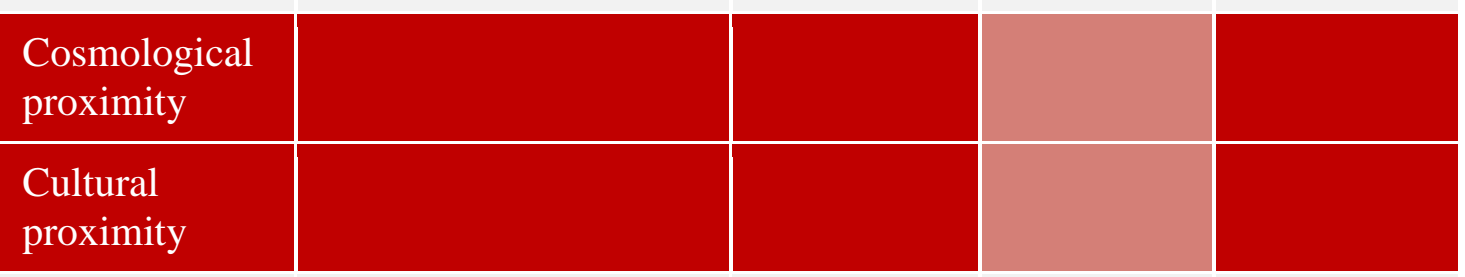

Environmental proximity

In this parallel proverb set, we see featured an idea of learning from experience as a means of gaining wisdom which interfaces both with cultural proximity and cosmological proximity with regard to the nature of the world's perceived structure. Again, we see similar overarching concepts as the fundamental determining factor for grouping these KiswaTwili proverbs into sets. It is also thought that these proverbs would be cited in similar contexts to convey the underlying philosophical thought that underpins each. In this set, we also see similar lexemes used to convey the concept for the first half of the proverb although there is divergence in the latter portion. Finally, we observe a similarity of syntax as each language employs a conditional sentence structure.

Having introduced and illustrated the PPP Matrix for several examples, however, due to space constraints, from here on we will present the parallel proverbs with a brief inter-textual reference to aforementioned dimensions of people proximity and proverb similarity as an appendix at the end of the paper. In doing so, we will continue to illustrate that the PPP Matrix as a conceptual framework can accommodate these additional parallel KiswaTwili proverbs and, further, could be successfully employed in any cross-cultural comparison of proverbs or any other cultural expression such as idioms, riddles, stories, etc. 


\subsection{Conclusion}

In the literature, several comparative studies on proverbs have been done from various perspectives. This paper has demonstrated a novel perspective from which a comprehensive comparison can be achieved.

Thus, it is clear that the PPP Matrix of Proximity and Similarity can be a useful way of presenting cross-culturally overlapping proverbs and representation of the degree to which they overlap. Further, we see that "People proximity" dimensions and "Proverb similarity" dimensions both provide insights into the Pan-African connections and unicity of worldview and culture with regard to the Akan and Waswahili 'Swahili people.' We also observed that despite being at a significant geographical distance $(6,287.4 \mathrm{~km} / 3,906.8 \mathrm{~km}$ from modern-day Ghana to Tanzania) proverbs are still demonstrably similar in a variety of dimensions as articulated in the analysis above. As such, we find that, indeed, greater closeness in one dimension may make up for greater distance in another.

In the future, we look forward to assembling an annotated corpus to determine the statistical frequencies of common lexemes found in a comprehensive Akan proverb corpus and a parallel Kiswahili proverb corpus. Another future research area of interest is in conducting an in-depth socio-linguistic study observing these proverbs in pragmatic context. Finally, we would like to engage in the translation of Akan proverbs into Kiswahili and vice-versa to enrich both languages and to enable greater social, cultural and economic exchange. 


\section{References}

Ampem, Agyewodin Adu Gyamfi. 1998. Akan mmebuscm bi. Kumasi: University Press.

Appiah, P., K.A. Appiah, and I. Agyeman-Duah. 2001. Bu Me Be: Akan Proverbs. Accra: Centre for Intellectual Renewal.

Dickson, Paul. 2006. Dictionary of Middle Egyptian in Gardiner Classification Order, December 1, 2006.

Dzahene-Quarshie, Josephine. 2016. Inalienable possession constructions in Akan and Swahili Kiswahili Vol. 79: 92-103.

Gluski, Jerzy. 1989. Proverbs: A Comparative Book of English, French, German, Italian, Spanish, and Russian Proverbs with a Latin Appendix: Elsevier Science Limited.

Holland, D., and N. Quinn. 1987. Cultural Models in Language and Thought: Cambridge University Press.

Hong-mei, DU. 2013. "On rhetoric characteristics of Anhui Mengcheng dialect proverb." Journal of Changchun Institute of Technology (Social Sciences Edition) 2:025.

Icke, Peter P. 2010. "The journey from language to experience: Frank Ankersmit's "lost historical cause." University of Southampton; University of Chichester.

King'ei, Kitula G, and Ahmed E Ndalu. 1989. Kamusi ya methali za Kiswahili. Nairobi: East African Publishers.

Lakoff, George, and Mark Johnson. 2008. Metaphors we live by: University of Chicago press.

Lojeski, Karen Sobel, and Richard R Reilly. 2008. Uniting the virtual workforce: Transforming leadership and innovation in the globally integrated enterprise. Vol. 2. Hoboken, NJ: John Wiley \& Sons.

Mensah, Eyo Offiong. 2010. "A morphosyntactic analysis of Efik proverbs." An Ambilingual Interdisciplinary Journal, Glossa 5 (2):250-281.

Meredith, M. 2011. Born in Africa: The Quest for the Origins of Human Life: Public Affairs.

Mieder, Wolfgang. 2003. Cognition, comprehension, and communication: a decade of North American proverb studies (1990-2000). Vol. 13: Schneider-Verlag Hohengehren.

Milke, Wilhelm, CD Chrétien, and AL Kroeber. 1949. "The Quantitative Distribution of Cultural Similarities and their Cartographic Representation." American Anthropologist 51 (2):237-252.

Moreno, Ana Ibáñez. 2005. "An analysis of the cognitive dimension of proverbs in English and Spanish: The conceptual power of language reflecting popular believes." SKASE Journal of Theoretical Linguistics 2 (1):42-54.

Mwambao. 2001. "Methali za Kiswahili ---- Swahili proverbs." Mwambao.com Accessed 20 June, 2015. http://www.mwambao.com/methali.htm.

Nabifar, Nesa. 2013. "A comparative study of English and Persian proverbs on bases of cognitive." 
Nurse, Derek, Thomas Spear, and Thomas T Spear. 1985. The Swahili: Reconstructing the history and language of an African society, 800-1500: University of Pennsylvania Press.

Obenga, Theophile. 1993. Origine Commune de l'Egyptien Ancien, du Copte et des Langues Negro-Africaines Modernes. Paris: L'Harmattan.

Opoku, Kofi Asare. 1997. Hearing and Keeping: Akan Proverbs. Accra: Ascmpa Publishers.

Osam, E. Kweku. 1993. "The loss of the noun class system in Akan." Acta Linguistica Hafniensia 26:81-106.

Owomoyela, O. 2005. Yoruba Proverbs. Lincoln, NE: University of Nebraska Press.

Pinto, Luisa Helena, Carlos Cabral Cardoso, and William Werther. 2010. "It is all in the mind: cultural distance, Psychic distance, and expatriation outcomes." 11th International HRM Conference.

Reindorf, C.C. 2007. History of the Gold Coast and Asante: Ghana Universities Press.

Rosch, Eleanor. 1978. "Principles of categorization "In Cognition and categorization, edited by E Rosch and B. B. Lloyd, 27-48. Hillsdale, NJ: Erlbaum.

Škara, Danica. 1995. "On the Structure of the Proverb: The Search for Associative Links." EUROPHRAS 95 Europaische Phraseologie im Vergleich: Gemeinsames Erbe und kulturelle Vielfalt.

Straubhaar, Joseph D, and Michael G Elasmar. 2003. "Choosing national TV: Cultural capital, language, and cultural proximity in Brazil. "The impact of international television: A paradigm shift: 77-110.

Ulatowska, Hanna K, Maria Sadowska, Danuta Kadzielawa, Jan Kordys, and Krystyna Rymarczyk. 2000. "Linguistic and cognitive aspects of proverb processing in aphasia." aphasiology 14 (3):227-250.

Vigilant, L., M. Stoneking, H. Harpending, K. Hawkes, and A. C. Wilson. 1991. "African populations and the evolution of human mitochondrial DNA." Science 253 (5027):1503-7.

Wamitila, K.W. 2001. Kamusi ya Methali. Nairobi: Longhorn Publishers.

Welmers, William E. 1963. "Associative a and ka in Niger-Congo.” Language: 432-447.

Ying, Chen. 2013. "A Comparative Analysis of the Concept of" Fortune and Woe" in Russian and Chinese Idioms and Proverbs." Journal of Beijing University of Aeronautics and Astronautics (Social Sciences Edition) 2:020. 


\section{APPENDIX}

KiswaTwili Proverb Set 7

11.

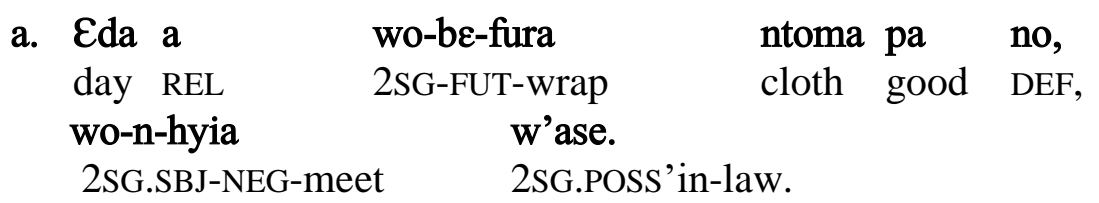

'On the day that you wear a good cloth, you don't meet your in-law.' (Appiah, Appiah, and Agyeman-Duah 2001: 68)

b. Siku u-ta-kayo-kwenda uchi, ndiyo siku u-ta-kayo-kutana-na day 2SG.SBJ-FUT-REL-go naked, indeed day 2SG-FUT-REL-meet-REFL na mkweo.

with in-law.

'The day you go naked is indeed the day you meet your in-law.' (King'ei and Ndalu 1989: 302)

Table 8: KiswaTwili Set 7 PPP Matrix

\begin{tabular}{|l|l|l|l|}
$\begin{array}{l}\text { Conceptual/Semantic } \\
\text { Similarity }\end{array}$ & $\begin{array}{l}\text { Contextual } \\
\text { Similarity }\end{array}$ & $\begin{array}{l}\text { Lexical } \\
\text { Similarity }\end{array}$ & $\begin{array}{l}\text { Syntactic/ } \\
\text { Structural } \\
\text { Similarity }\end{array}$ \\
\hline
\end{tabular}

Biological

proximity

Cosmological

proximity

Cultural

proximity
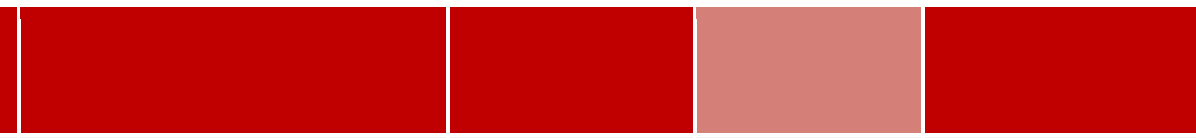

Environmental

proximity 
KiswaTwili Proverb Set 8

12.

a. Aboa bi reka wo a, animal INDEF PROG-bite 2SG.OBJ COND, o-firi wo ntoma mu. 3SG.SBJ-from 2SG.POSS cloth inside. If a bug will bite you, it's from inside your cloth.' (Appiah, Appiah, and Agyeman-Duah 2001: 52)

b. Ki-kula-cho ki nguoni mwako. thing-eat-2SG.OBJ-REL thing cloth-inside 2SG.POSS 'That which eats at you is inside your cloth.' (Wamitila 2001: 102)

Table 9: KiswaTwili Set 8 PPP Matrix

\begin{tabular}{l|l|ll}
$\begin{array}{l}\text { Conceptual/Semantic } \\
\text { Similarity }\end{array}$ & $\begin{array}{l}\text { Contextual } \\
\text { Similarity }\end{array}$ & $\begin{array}{l}\text { Lexical } \\
\text { Similarity }\end{array}$ & $\begin{array}{l}\text { Syntactic/ } \\
\text { Structural } \\
\text { Similarity }\end{array}$
\end{tabular}

Biological

proximity

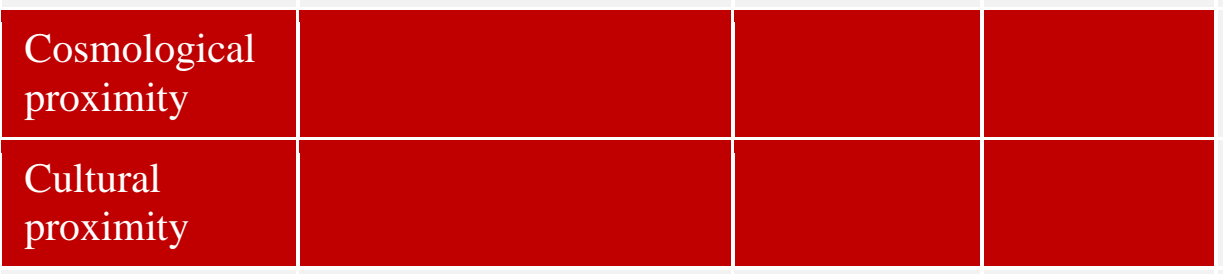

Environmental proximity 
KiswaTwili Proverb Set 9

13.

a. Wo-ton w'asem

$$
\begin{array}{cll}
\text { a, } & \text { na } & \text { wo-nya } \\
\text { 2SG.POSS'issue COND } & & \text { FOC 2SG.SBJ-get }
\end{array}
$$

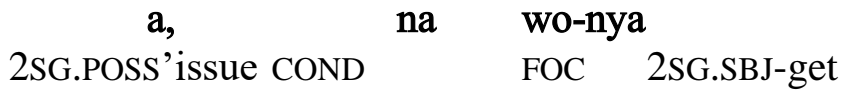

2SG.SBJ-sell

tofoo.

buyer

'If you sell your case, you get a buyer.' (When you explain your difficulties convincingly, you get help). (Appiah, Appiah, and Agyeman-Duah 2001: 280)

b. Eleza haja explain need

haja.

'Explain your need, get what you need.' (Wamitila 2001: 61)

Table 10: KiswaTwili Set 9 PPP Matrix

\begin{tabular}{l|lll} 
Conceptual/Semantic & $\begin{array}{l}\text { Contextual } \\
\text { Similarity }\end{array}$ & $\begin{array}{l}\text { Lexical } \\
\text { Similarity }\end{array}$ & $\begin{array}{l}\text { Syntactic/ } \\
\text { Structural } \\
\text { Similarity }\end{array}$
\end{tabular}

Biological

proximity

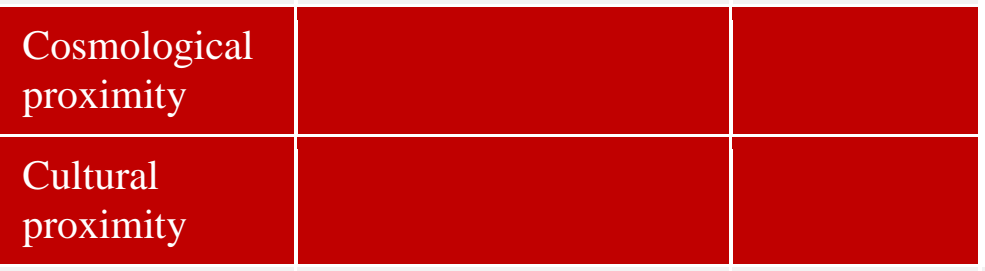

Environmental

proximity 
KiswaTwili Proverb Set 10

14.

a. Dee owo aka no, suro sonsono.

REL snake bite 3SG.OBJ, fear earthworm

'One who has been bitten by a snake fears a worm.' (Appiah, Appiah, and Agyeman-Duah 2001: 85)

b. Mtafunwa na nyoka akiona unyasi (ung'ongo/ukuti)

NOM-bite.PASS by snake 3SG.INAN-see reed (palm leaf/twig)

hu-shtuka.

HAB-startle

'One who has been bitten by a snake is startled at the sight of a reed.' (Wamitila 2001: 186)

Table 11: KiswaTwili Set 10 PPP Matrix

\begin{tabular}{l|l|l|l|} 
Conceptual/Semantic & $\begin{array}{l}\text { Contextual } \\
\text { Similarity }\end{array}$ & $\begin{array}{l}\text { Lexical } \\
\text { Similarity }\end{array}$ & $\begin{array}{l}\text { Syntactic/ } \\
\text { Structural } \\
\text { Similarity }\end{array}$ \\
\hline
\end{tabular}

Biological

proximity

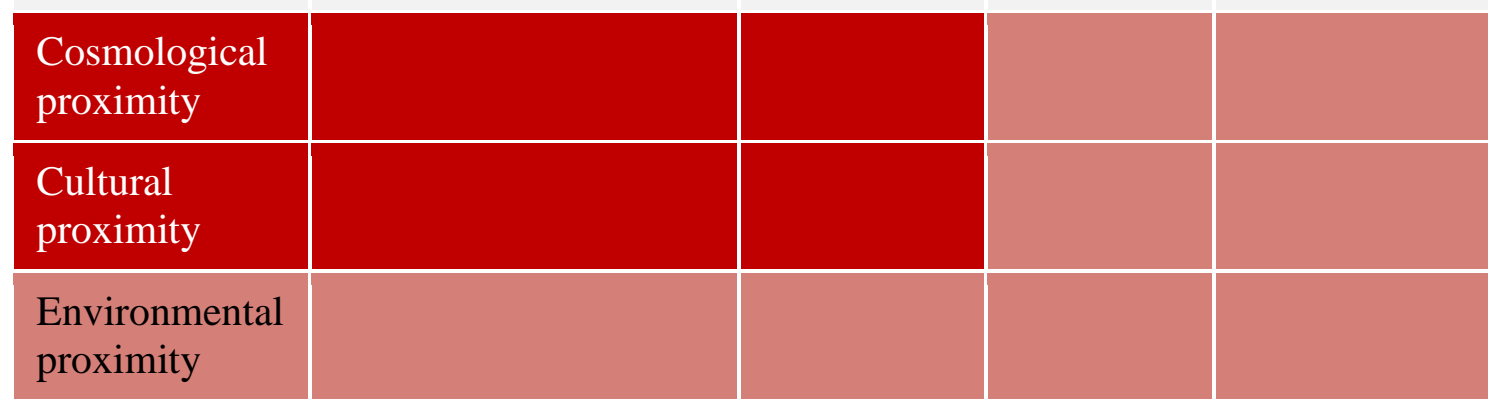


KiswaTwili Proverb Set 11

15.
a. Woto
adubone
a,
ebi ka w'ano
2SG.SBJ-throw poison
COND,
some touch 2SG.POSS'mouth

'When you make poison, some touches your mouth.' (Appiah, Appiah, and Agyeman- Duah 2001: 276)
b. Wope se egu wo sonk 2SG.SBJ-like like 3SG.INAN-fall 2sG.POSS neighbor on COND, Egu wo sos.

3SG.INAN-fall 2SG.OBJ on

'If you want it (evil) to fall on your neighbor, it falls on you.' (Opoku 1997: 13)
c. Mchimba kisima huingia mwenyewe.

digger pit enter 3SG.REFL

'He who digs a pit falls into it himself.' (Wamitila 2001: 216)

d. Mcheza na tope hum-rukia. player with mud 3PL.SBJ-jump

'Mud splashes the one who plays with it.' (Wamitila 2001: 156)

Table 12: KiswaTwili Set 11 PPP Matrix

\begin{tabular}{|c|c|c|}
\hline $\begin{array}{l}\text { Conceptual/Semantic } \\
\text { Similarity }\end{array}$ & $\begin{array}{l}\text { Contextual } \\
\text { Similarity }\end{array}$ & $\begin{array}{l}\text { Lexical } \\
\text { Similarity }\end{array}$ \\
\hline
\end{tabular}

Biological

proximity

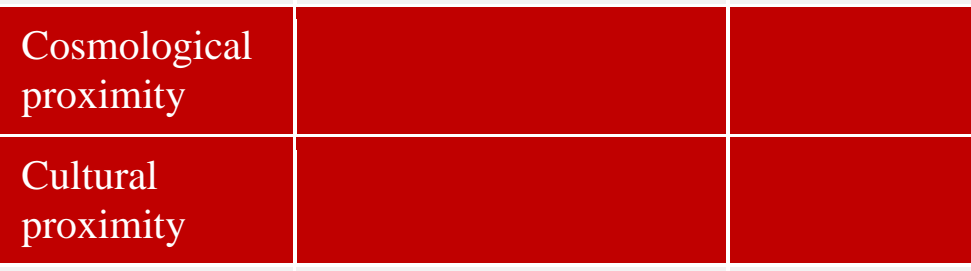

Environmental proximity 
KiswaTwili Proverb Set 12

16.

a. Nkakrankakra akoko be-nom nsuo.

little-little chicken FUT-drink water

'Little by little the chicken will drink water.'

b. Haba na haba hujaza kibaba.

Little and little fill pot

'Little by little, the container gets filled.' (Wamitila 2001: 265)

Table 13: KiswaTwili Set 12 PPP Matrix

\begin{tabular}{l|l|l|l} 
Conceptual/Semantic & Contextual \\
Similarity & Similarity & $\begin{array}{l}\text { Lexical } \\
\text { Similarity }\end{array}$ & $\begin{array}{l}\text { Syntactic/ } \\
\text { Structural } \\
\text { Similarity }\end{array}$
\end{tabular}

\section{Biological \\ proximity}

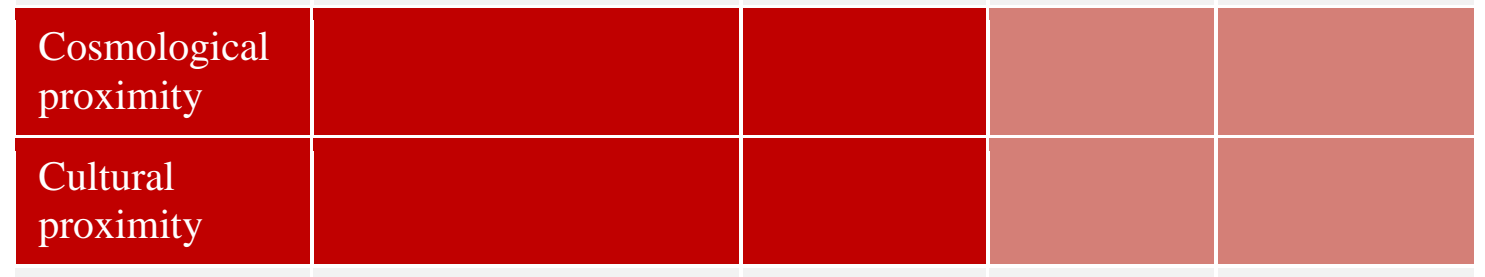

Environmental

proximity 
KiswaTwili Proverb Set 13

17.

a. Abaa a ye-de bo Takyi no, eno ara stick REL 1PL-take strike T. DEF 3SG.INAN merely na ye-de bo Baa.

FOC 1PL-take strike B.

'The stick that we use to beat Takyi is the one that we use to beat Baa.' (Appiah, Appiah, and Agyeman-Duah 2001: 14)

b. Fimobo impigaye

mke mwenzio u-ki-ona

cane 3SG.INAN-beat-INS wife colleague 2SG-COND-see

i-tup-e nje.

3SG.INAN-dispose-SBJV out

'When you see the cane which beat your fellow wife, throw it away.'

Table 14: KiswaTwili Set 13 PPP Matrix

\begin{tabular}{l|l|ll}
$\begin{array}{l}\text { Conceptual/Semantic } \\
\text { Similarity }\end{array}$ & $\begin{array}{l}\text { Contextual } \\
\text { Similarity }\end{array}$ & $\begin{array}{l}\text { Lexical } \\
\text { Similarity }\end{array}$ & $\begin{array}{l}\text { Syntactic/ } \\
\text { Structural } \\
\text { Similarity }\end{array}$
\end{tabular}

Biological

proximity

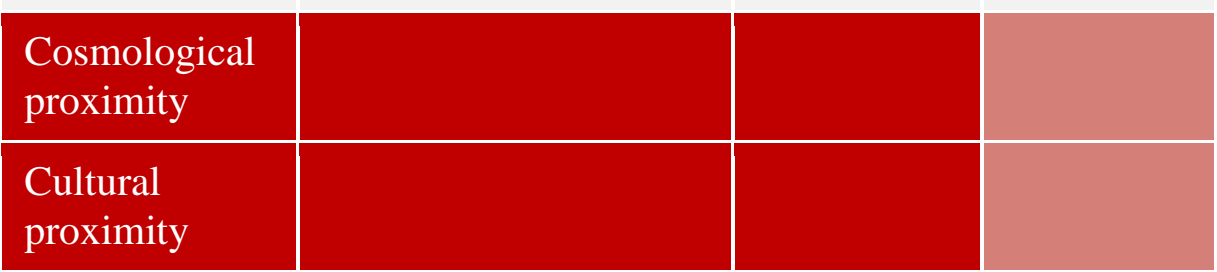

Environmental

proximity 
KiswaTwili Proverb Set 14

18.

$\begin{array}{llll}\text { a. Bede } & \text { ayeyie ne } & \text { sumina } & \text { so. } \\ \text { carrying-basket } & \text { thanks be } & \text { rubbish-heap } & \text { on }\end{array}$

'The carrying basket's thanks is the rubbish heap.' (Appiah, Appiah, and Agyeman-Duah 2001: 25)

$\begin{array}{llll}\text { b. Fadhila ya } & \text { punda } & \text { ni } & \text { mateke (mashuzi). } \\ \text { gratitude GEN } & \text { donkey } & \text { be } & \text { kicks (farts) }\end{array}$

'The gratitude of a donkey is kicks (farts).' (Mwambao 2001)

Table 15: KiswaTwili Set 14 PPP Matrix

\begin{tabular}{|l|l|l|l|} 
Conceptual/Semantic & $\begin{array}{l}\text { Contextual } \\
\text { Similarity }\end{array}$ & $\begin{array}{l}\text { Lexical } \\
\text { Similarity }\end{array}$ & $\begin{array}{l}\text { Syntactic/ } \\
\text { Structural } \\
\text { Similarity }\end{array}$ \\
\hline
\end{tabular}

Biological

proximity

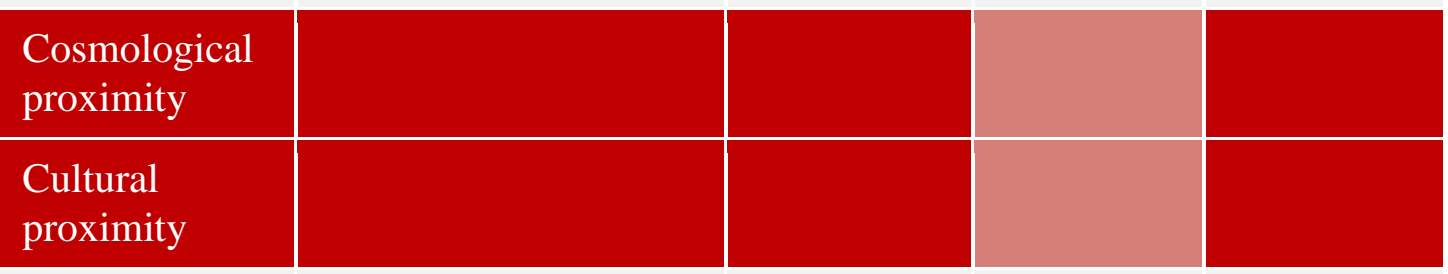

Environmental

proximity 
Kambon \& Dzahene-Quarshie: TwiSwahili or KiswaTwili: A Study of Parallel Proverbs in Akan (Twi) and Kiswahili

KiswaTwili Proverb Set 15

19.

3SG.INAN-belong 1SG.OBJ CONJ 3SG.INAN-belong 1PL.OBJ

$\varepsilon-\mathrm{n}-\mathrm{s} \varepsilon$.

3SG-NEG-resemble

'It belongs to me and it belongs to us is not the same.'

b. Changu ni bora kuliko chetu.

1SG.POSS be better than 3PL.POSS

'Mine is better than ours.' (Wamitila 2001: 48)

Table 16: KiswaTwili Set 15 PPP Matrix

\begin{tabular}{l|l|l|l} 
Conceptual/Semantic & $\begin{array}{l}\text { Contextual } \\
\text { Similarity }\end{array}$ & $\begin{array}{l}\text { Lexical } \\
\text { Similarity }\end{array}$ & $\begin{array}{l}\text { Syntactic/ } \\
\text { Structural } \\
\text { Similarity }\end{array}$ \\
\hline
\end{tabular}

Biological

proximity

Cosmological

proximity

Cultural

proximity

Environmental

proximity 
KiswaTwili Proverb Set 16

20.

a. Ade-pa na $\varepsilon$-ton $\quad$ ne thing-good FOC 3SG.INAN-sell 3SG.POSS REFL 'A good thing sells itself.' (Appiah, Appiah, and Agyeman-Duah 2001: 90)

b. Ki-zuri cha-ji-uza ki-baya chaji-tembeza. thing-good thing-REFL-sell thing-bad thing-REFL-advertise 'The thing sells itself, the bad goes round itself (looking for a buyer).' (Wamitila 2001: 49)

Table 17: KiswaTwili Set 16 PPP Matrix

\begin{tabular}{l|l|l|l|}
$\begin{array}{l}\text { Conceptual/Semantic } \\
\text { Similarity }\end{array}$ & $\begin{array}{l}\text { Contextual } \\
\text { Similarity }\end{array}$ & $\begin{array}{l}\text { Lexical } \\
\text { Similarity }\end{array}$ & $\begin{array}{l}\text { Syntactic/ } \\
\text { Structural } \\
\text { Similarity }\end{array}$ \\
\hline
\end{tabular}

Biological

proximity

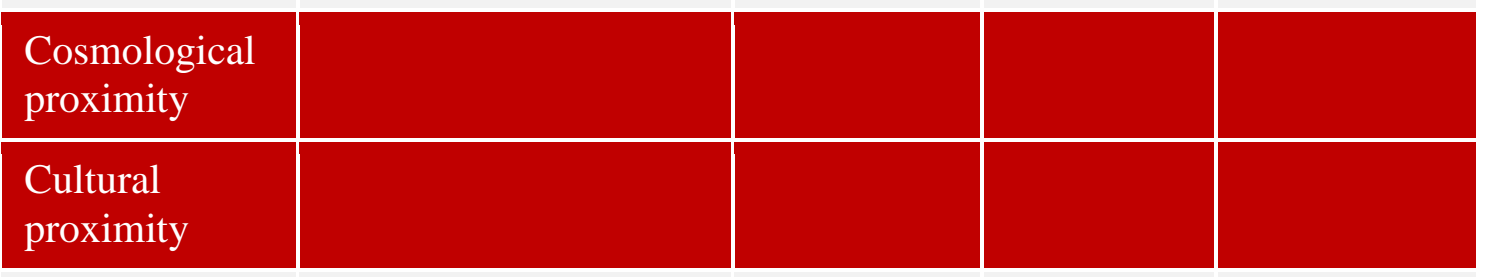

Environmental proximity 
KiswaTwili Proverb Set 17

21.

a. De $\operatorname{ade}$ wo no na odie

REL thing have/belong 3SG.OBJ FOC 3SG.SBJ-eat

na $\varepsilon$-n-ye dee $\varepsilon$ kom de no

FOC 3SG.INAN-NEG-be REL hunger take 3SG.OBJ

'The one who the thing belongs to eats it, not the one who is hungry.' (Appiah, Appiah, and Agyeman-Duah 2001: 77)

b. Cha wenyewe huliwa na wenyewe.

GEN 3PL.REFL consume-pass by 3PL.REFL

'What is theirs is consumed by themselves.' (Wamitila 2001: 46)

Table 18: KiswaTwili Set 17 PPP Matrix

\begin{tabular}{l|l|ll} 
Conceptual/Semantic & $\begin{array}{l}\text { Contextual } \\
\text { Similarity }\end{array}$ & $\begin{array}{l}\text { Lexical } \\
\text { Similarity }\end{array}$ & $\begin{array}{l}\text { Syntactic/ } \\
\text { Structural } \\
\text { Similarity }\end{array}$
\end{tabular}

Biological

proximity

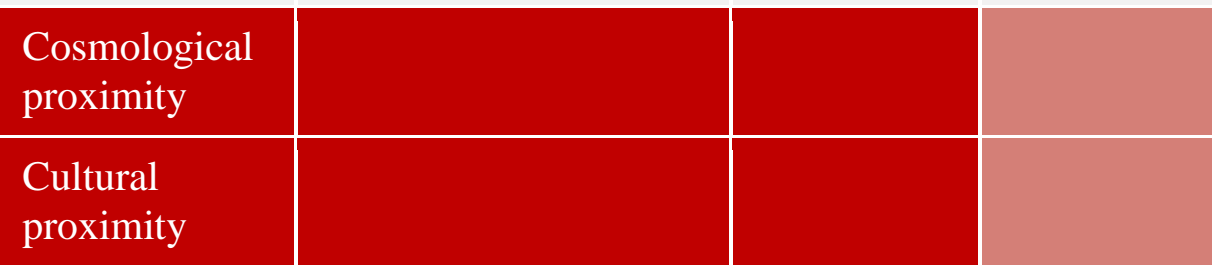

Environmental

proximity 
KiswaTwili Proverb Set 18

22.
a. Dyare a
$\varepsilon$-be-kum
wo
bo wo
sickness REL
a,
3SG.INAN-FUT-kill
2SG.OBJ
strike $2 \mathrm{SG}$

COND 2SG-NEG-remember medicine-maker.

'When the illness that is destined to kill you strikes you, you don't remember the medicine man (who could cure you).' (Opoku 1997: 53)
b. Sikio la
ear GEN
kufa
halisikii
dawa.
NEG-3SG-hear
medicine
'The ear of death does not hear medication.' (Wamitila 2001: 257)

Table 19: KiswaTwili Set 18 PPP Matrix

\begin{tabular}{l|l|l}
$\begin{array}{l}\text { Conceptual/Semantic } \\
\text { Similarity }\end{array}$ & $\begin{array}{l}\text { Contextual } \\
\text { Similarity }\end{array}$ & $\begin{array}{l}\text { Lexical } \\
\text { Similarity }\end{array}$ \\
\hline
\end{tabular}

\section{Biological \\ proximity \\ Cosmological \\ proximity}

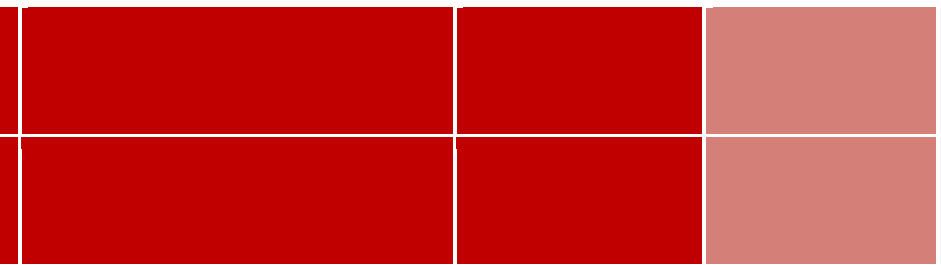

Cultural

proximity

Environmental

proximity 
KiswaTwili Proverb Set 19

23.

a. Wo-hunu

2SG.SBJ-see re-hye PROG-burn ho.

body

'When you see someone's beard is burning, you put water by your own.' (Appiah, Appiah, and Agyeman-Duah 2001: 131)

b. Mwenzako akinyolewa

chako kitie

fellow 3SG-COND-shave 2SG put-IMPER water

'When you see your friend being shaved, put water on yours (in preparation for you could be the next).' (Wamitila 2001: 217)

Table 20: KiswaTwili Set 19 PPP Matrix

\begin{tabular}{|l|l|l|l|}
$\begin{array}{l}\text { Conceptual/Semantic } \\
\text { Similarity }\end{array}$ & $\begin{array}{l}\text { Contextual } \\
\text { Similarity }\end{array}$ & $\begin{array}{l}\text { Lexical } \\
\text { Similarity }\end{array}$ & $\begin{array}{l}\text { Syntactic/ } \\
\text { Structural } \\
\text { Similarity }\end{array}$ \\
\hline
\end{tabular}

Biological

proximity

Cosmological proximity

Cultural

proximity
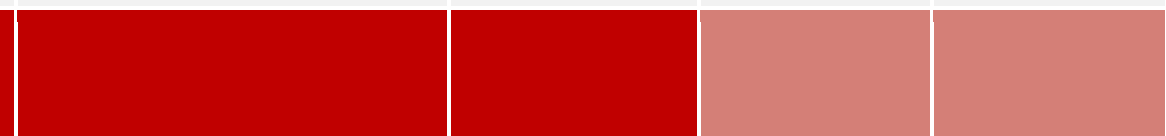

Environmental

proximity 
KiswaTwili Proverb Set 20

24.

a. Obi n-kyere stomfos ba atono. someone NEG-show blacksmith child smithing 'No one shows the blacksmith's child smithing.' (Appiah, Appiah, and Agyeman-Duah 2001: 38)

$\begin{array}{lllll}\text { b. Obi } & \text { n-kyere } & \text { osebo } & \text { ba } & \text { atoo. } \\ \text { someone } & \text { NEG-show } & \text { leopard } & \text { child } & \text { springing }\end{array}$

'No one shows the leopard's child springing.' (Appiah, Appiah, and Agyeman-Duah 2001: 37)

c. Mwana wa kuku ha-funz-wi

offspring GEN chicken NEG-teach-PASS

kuchakura.

INF-scratch-ground

'The chicken is not taught how to scratch the ground.' (Wamitila 2001: 206)

Table 21: KiswaTwili Set 20 PPP Matrix

\begin{tabular}{l|l|l|l} 
Conceptual/Semantic & $\begin{array}{l}\text { Contextual } \\
\text { Similarity }\end{array}$ & $\begin{array}{l}\text { Lexical } \\
\text { Similarity }\end{array}$ & $\begin{array}{l}\text { Syntactic/ } \\
\text { Structural } \\
\text { Similarity }\end{array}$
\end{tabular}

\section{Biological \\ proximity \\ Cosmological \\ proximity}
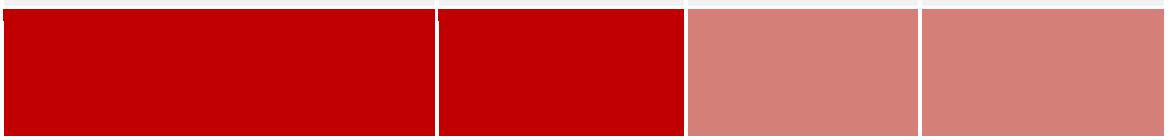

Cultural

proximity

Environmental

proximity 
KiswaTwili Proverb Set 21

25.

a. Nea o-da ne gya na o-nim REL 3SG-lay 3SG.POSS fire FOC 3sG-know manner $\varepsilon$-hyehye no.

3SG.INAN-burn-burn 3SG

'The one sitting next to the fire knows how it burns him/her.' (Ampem 1998: 91)

$\begin{array}{lll}\text { kilala } & \text { hujui } & \text { kunguni } \\ \text { sleep } & \text { 2SG-NEG-know } & \text { bedbugs }\end{array}$

bed 2SG.NEG-REL-have sleep 2SG-NEG-know bedbugs

wake.

3SG.POSS

'You do not know the bugs in a bed on which you have not slept.' (Wamitila 2001: 110)

Table 22: KiswaTwili Set 21 PPP Matrix

\begin{tabular}{|l|l|l|l|}
$\begin{array}{l}\text { Conceptual/Semantic } \\
\text { Similarity }\end{array}$ & $\begin{array}{l}\text { Contextual } \\
\text { Similarity }\end{array}$ & $\begin{array}{l}\text { Lexical } \\
\text { Similarity }\end{array}$ & $\begin{array}{l}\text { Syntactic/ } \\
\text { Structural } \\
\text { Similarity }\end{array}$ \\
\hline
\end{tabular}

Biological

proximity

Cosmological

proximity

Cultural

proximity

Environmental

proximity 
KiswaTwili Proverb Set 22

26.
a. Shohoo na o-di akoko a n'ani guest FOC 3SG-eat chicken REL 3SG.POSs'eye a-bo.
PRF-burst
'It is the stranger who eats the blind chicken.' (Ampem 1998: 136)

b. Shohoo n-te dee ne boto re-tee. guest NEG-hear REL 3SG.POSS bag PROG-hear

'The visitor does not hear what his luggage hears.' (Ampem 1998: 136)

c. Kutu kuu ni la mgeni.

rust old be GEN stranger

'Old rust is for the stranger.' (Wamitila 2001: 124)

Table 23: KiswaTwili Set 22 PPP Matrix

\begin{tabular}{|l|l|l|l|}
$\begin{array}{l}\text { Conceptual/Semantic } \\
\text { Similarity }\end{array}$ & $\begin{array}{l}\text { Contextual } \\
\text { Similarity }\end{array}$ & $\begin{array}{l}\text { Lexical } \\
\text { Similarity }\end{array}$ & $\begin{array}{l}\text { Syntactic/ } \\
\text { Structural } \\
\text { Similarity }\end{array}$ \\
\hline
\end{tabular}

Biological

proximity

Cosmological

proximity

\section{Cultural \\ proximity}

Environmental

proximity 